
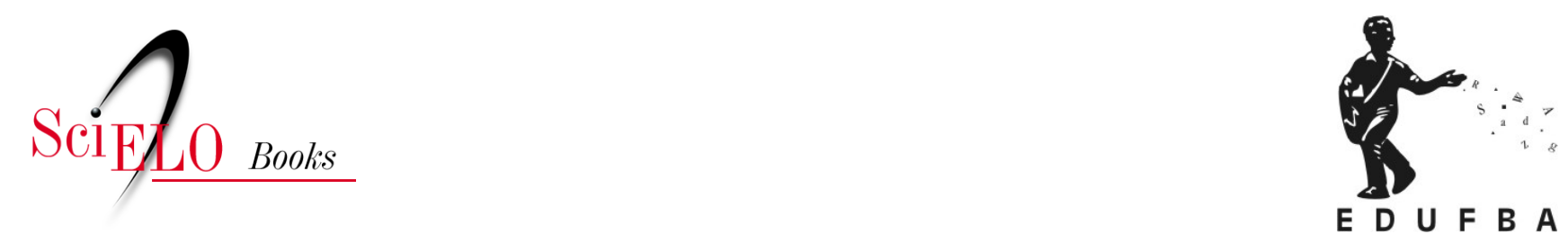

\title{
Parte I \\ Elementos teóricos para compreensão das redes de atenção à saúde
}

\author{
Adriano Maia dos Santos
}

\section{SciELO Books / SciELO Livros / SciELO Libros}

SANTOS, A.M. Elementos teóricos para compreensão das redes de atenção à saúde. In: Redes regionalizadas de atenção à saúde: desafios à integração assistencial e à coordenação do cuidado [online]. Salvador: EDUFBA, 2018, pp. 35-83. ISBN 978-85-232-2026-6.

https://doi.org/10.7476/9788523220266.0004.

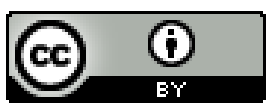

All the contents of this work, except where otherwise noted, is licensed under a Creative Commons Attribution 4.0 International license.

Todo o conteúdo deste trabalho, exceto quando houver ressalva, é publicado sob a licença Creative Commons Atribição 4.0. 
PARTE I

\section{ELEMENTOS TEÓRICOS PARA COMPREENSÃO DAS REDES DE ATENÇÃO À SAÚDE}




\section{Capítulo I}

\section{COMPONENTES ESTRATÉGICOS DA REGIONALIZAÇÃO PARA GESTÃO DO CUIDADO EM REDES DE ATENÇÃO}

A descentralização é um fenômeno global que ganhou impulso no Brasil a partir da década de 1990 e, em certa medida, nas políticas do setor saúde, ampliou a cobertura e favoreceu o acesso da população a serviços e ações de saúde, mobilizou a organização dos serviços baseados em problemas de interesse local e na incorporação de novos atores sociais, além de viabilizar uma maior participação e controle social na definição e execução orçamentária dos gastos em saúde, reforçando a autonomia e a responsabilidade de cada ente subnacional. (GUIMARÃES; GIOVANELLA, 2004) Apesar disso, a descentralização esbarra na assimetria financeira e gestora dos distintos níveis de governo, bem como na permeabilidade das instituições de saúde à democracia, impondo constrangimentos que mitigam a potência dos demais princípios e diretrizes do SUS e complexificam a consolidação de uma política nacional de saúde, cujo modelo federativo é trino, sem uma vinculação hierárquica entre os entes (União, estados e municípios), reforçando, muitas vezes, a competição frente à cooperação. (LEVCOVITZ; LIMA; MACHADO, 2001) 
Essa problemática é debatida por Campos (2006), ao argumentar que o desenho forjado pela descentralização da política de saúde brasileira concebeu um sistema peculiar, no qual a responsabilidade pela organização e gestão local é do município (menor instância com poder formal na República), diferindo, por exemplo, do caráter nacional inglês, português e cubano ou o provincial canadense e o autônomo espanhol. Todavia, a descentralização por si só não é suficiente para viabilizar os princípios e diretrizes do SUS, criando até mesmo efeitos paradoxais. Por um lado, responde ao valor ético-político almejado pelo espírito democrático ao possibilitar a distribuição de poder e ampliação dos mecanismos de participação social; por outro, as forças geradas pela descentralização podem produzir um funcionamento autárquico, potencializando a indesejável fragmentação do sistema, "gerando um processo de municipalização com baixa capacidade de integração e de solidariedade entre as partes". (CAMPOS, 2006, p. 427)

Algumas evidências - a partir da análise de implantação da descentralização na gestão do SUS em cinco municípios da Bahia, selecionadas como "casos exemplares" (VIEIRA-DA-SILVA et al., 2007) - revelaram aspectos positivos, como a ampliação da cobertura assistencial de ações básicas e a ampliação do acesso a serviços de média e alta densidade tecnológica; porém, muito mais atrelados à indução ministerial que relacionados à ação local, sugerindo limites na capacidade propositiva municipal ou insuficiência técnica. Além disso, apesar do grau avançado de descentralização da "gestão plena do sistema", constataram-se muitas heterogeneidades entre os municípios investigados, não significando "melhorias automáticas na gestão, na organização das práticas e nos seus efeitos”, ou seja, "a descentralização em si, não foi capaz de assegurar mudanças nos sistemas locais de saúde”. (VIEIRA-DA-SILVA et al., 2007, p. 366)

Por esse prisma, as disparidades entre os municípios por condições geográficas, demográficas, políticas, técnico-administrativas, socioeconômicas e financeiras, além da complexidade de demandas e 
necessidades da população, evidenciam uma série de problemas cujo enfrentamento transpõe o território municipal, posto que "o alcance da integralidade depende da articulação dos sistemas municipais de atenção em redes regionais". (GUIMARÃES; GIOVANELLA, 2004, p. 287) Com efeito, expõe a necessidade de articulações intermunicipais que abram espaço para “[...] a profusão de novas formas de relação entre Estado e sociedade, colocando no âmbito da discussão pública os alicerces da estrutura de poder, organização e gestão das instituições políticas vigentes" (FLEURY; OUVERNEY, 2007, p.11), conferindo um novo modelo de governança que alie a descentralização à necessidade de integração solidária.

Para Fleury e Ouverney (2007), a proliferação de redes gestoras de políticas públicas é um fenômeno mundial, sobretudo no campo das políticas sociais, num cenário de adensamentos do tecido social resultante dos processos de descentralização e democratização nas sociedades latino-americanas. A gestão de redes tenta responder à complexidade de problemas que envolvem múltiplos atores sociais em estruturas policêntricas, que interagem para permitir maior flexibilidade, integração e interdependência, "onde há interação de agentes públicos e privados, centrais e locais, bem como uma crescente demanda por benefícios e por participação cidadã”. (FLEURY; OUVERNEY, 2007, p. 10)

A gestão do cuidado em rede regionalizada, na perspectiva de um sistema integrado, é vital no cerne de uma política social como o SUS, haja vista o conjunto de problemas de saúde cujo enfrentamento transcende a capacidade gestora de apenas um ente subnacional, ou seja, pauta-se na necessidade de um sistema articulado, interdependente e cooperativo, tendo "[...] múltiplas dimensões de integração entre diferentes subsistemas relacionando a Clínica e a Governança às representações e valores coletivos”. (HARTZ; CONTANDRIOPOULOS, 2004, p. 332)

Tal reconhecimento foi traduzido na Lei $\mathrm{n}^{\circ}$ 8.080/90 (BRASIL, 1990a) como uma das diretrizes organizacionais do SUS - a regionalização - e foi sendo atualizado, não necessariamente priorizado, a cada nova Norma Operacional Básica (NOB), num misto de avanços e 
contradições. (SANTOS; ANDRADE, 2007) Assim, as NOB regularam e orientaram a descentralização e, em certa medida, permitiram um insulamento da regionalização. (LEVCOVITZ; LIMA; MACHADO, 2001) Porquanto, em países europeus, as agendas de descentralização e regionalização caminharam articulando-se; enquanto nos países latinoamericanos, inclusive no Brasil, houve agendas distintas entre elas, com maior destaque para a descentralização. Sendo assim, os mecanismos de integração para construção de um sistema regionalizado ficaram em segundo plano. (VIANA; LIMA; FERREIRA, 2010)

Todas essas questões, sobretudo o atraso da regionalização no SUS, arrefeceram a capacidade resolutiva dos sistemas locais de saúde, amplificando disputas por recursos entre os municípios, ao invés de conformar uma rede interdependente e cooperativa. Nessa seara, a ausência de planejamento regional para as estratégias de descentralização no SUS acirrou as desigualdades dos entes subnacionais, fragilizou e comprometeu o papel das esferas estaduais, resultando, no final da década de 1990, em milhares de sistemas locais isolados, muito dos quais sem capacidade de gestão do cuidado em todas as dimensões para viabilizar a integralidade e sem mecanismos e expertise para conformação de redes intermunicipais. (NORONHA; LIMA; MACHADO, 2008; VIANA et al., 2008; VIANA; LIMA; FERREIRA, 2010)

Somente no início dos anos 2000, foram estabelecidas as estratégias de normatização para constituição de redes regionalizadas de saúde por meio da Norma Operacional da Assistência à Saúde (Noas), reatualizando o tema "regionalização" na agenda dos gestores do SUS, além de resgatar o papel dos estados na condução desse processo. (LIMA et al., 2010; VIANA et al., 2008) Entretanto, manteve as prioridades da população, em cada município, como princípios organizadores da oferta dos serviços de referência, na lógica da territorialidade. (GIOVANELLA et al., 2002)

Uma das ferramentas propostas pela Noas foi o Plano Diretor de Regionalização (PDR), sob responsabilidade do gestor estadual, para 
ordenamento do processo de regionalização em cada unidade federativa. Tal dispositivo deveria viabilizar o acesso das pessoas aos serviços de saúde em qualquer nível de atenção, sendo disponibilizada a tecnologia mais adequada para resolver os problemas de saúde no município de residência ou mediante programações intermunicipais. Além do PDR, foram propostos o Plano Diretor de Investimento (PDI) e a própria Programação Pactuada e Integrada (PPI) como instrumentos para planejamento e operacionalização da regionalização. Contudo, apesar de estimular o planejamento regional na esfera estadual, a Noas foi criticada pela excessiva normatização e rigidez das suas ferramentas para implementação da gestão do cuidado em redes. Além disso, não logrou superar a competição entre os municípios, nem avançou na questão da governança regional. (NASCIMENTO, 2007; VIANA et al., 2008; VIANA; LIMA; FERREIRA, 2010)

A regionalização é um atributo dos sistemas nacionais de saúde que se organizam para ampliar o acesso e diminuir as desigualdades, posto que, intrinsecamente, é derivada dos princípios de universalidade e equidade. (KUSCHNIR; CHORNY, 2010) Não obstante, a regionalização deve viabilizar a utilização da tecnologia mais adequada ao cuidado em tempo e local oportunos, em qualquer parte do território, guiada por uma racionalidade sistêmica que contemple cooperativamente as disparidades na distribuição dos diferentes serviços e recursos necessários à integralidade, além da articulação intersetorial. (NORONHA; LIMA; MACHADO, 2008)

Em cenários concretos, estudos sobre a regionalização evidenciam as dificuldades na consolidação de um "governo regional” diante da insuficiência no financiamento, das frágeis políticas de gestão do trabalho e de constrangimentos na oferta de serviços e nos tempos de espera. (LOPES, 2010) Além disso, influência e interferência do setor privado no SUS em todo processo de regionalização (COELHO, 2011), bem como conflito e disputa entre gestores à revelia da discussão regional (IANNI et al., 2012), comprometem a coesão intermunicipal para integração de 
serviços. Destaca-se, por sua vez, o papel estratégico do gestor estadual na indução da regionalização (PEREIRA, 2009) e a constituição de colegiados regionais. (LOPES, 2010) Essas pesquisas revelam que, em contraposição à imagem-objetivo que modela os ganhos com a regionalização, sua implementação tem sido complexa e incremental, alternando avanços e retrocessos.

O Ministério da Saúde, buscando superar esses limites, publicou a Portaria 399GM, de 22 de fevereiro de 2006, que contempla as Diretrizes do Pacto pela Saúde (pela Vida, de Gestão e em Defesa do SUS), com a qual sugere novas bases de negociação para o financiamento, definição de responsabilidades, metas sanitárias e compromisso entre as três esferas de gestão do SUS. O referido documento propõe mudanças significativas para a execução do SUS, retomando a regionalização como diretriz fulcral nas políticas de gestão do cuidado à saúde nos territórios. Para tanto, revisita e atualiza os instrumentos experimentados na Noas (PDR, ${ }^{2} \mathrm{PDI}^{3}$ e $\mathrm{PPI}^{4}$ ), alicerçando-os num conjunto de reformas institucionais pactuadas entre os três entes federados, substituindo o processo de habilitação por adesão solidária aos Termos de Compromisso de Gestão. Desse modo, também constitui espaços regionais de planejamento e cogestão,

2 O PDR deverá expressar o desenho final do processo de identificação e reconhecimento das regiões de saúde em suas diferentes formas, em cada estado e no Distrito Federal, objetivando a garantia do acesso, a promoção da equidade, a garantia da integralidade da atenção, a qualificação do processo de descentralização, a racionalização de gastos e otimização de recursos. (BRASIL, 2006a, p. 18)

$3 \mathrm{O}$ PDI deve expressar os recursos de investimentos para atender às necessidades pactuadas no processo de planejamento regional e estadual. No âmbito regional, este deve refletir as necessidades para se alcançar a suficiência na Atenção Básica e parte da média complexidade da assistência, conforme desenho regional e na macrorregião no que se refere à alta complexidade. (BRASIL, 2006a, p. 18)

4 PPI é um processo instituído no âmbito do SUS, em que, em consonância com o processo de planejamento, são definidas e quantificadas as ações de saúde para a população residente em cada território, bem como efetuados os pactos intergestores para garantia de acesso da população aos serviços de saúde. Tem por objetivo organizar a rede de serviços, dando transparência aos fluxos estabelecidos, e definir, a partir de critérios e parâmetros pactuados, os limites financeiros destinados à assistência da população própria e das referências recebidas de outros municípios. (BRASIL, 2006b, p. 13) 
representados pelos Colegiados de Gestão Regional (CGR), num processo de "regionalização viva". (BRASIL, 2006a, 2007)

Os documentos do Pacto pela Saúde orientam para a constituição de Regiões de Saúde tendo como ponto de partida o PDR, mas fazendo as devidas composições que respondam adequadamente às dinâmicas dos territórios, favorecendo a ação cooperativa intergestora. Para tanto, destacam o papel coordenador do Estado, a importância do Conselho de Secretários Municipais de Saúde (Cosems), da Comissão Intergestora Bipartite (CIB) e dos CGR como espaços de articulação dos gestores municipais. Estes devem propor o desenho da Região de Saúde com baliza nas identidades culturais, econômicas e sociais, assim como na distribuição da infraestrutura, comunicação, transporte e saúde, visando garantir amplo acesso e promovendo a equidade e a integralidade do cuidado. Por sua vez, a depender das características geopolíticas, as Regiões de Saúde podem ser intramunicipais, intraestaduais, intermunicipais, interestaduais e fronteiriças. (BRASIL, 2007, 2009)

De acordo com Viana, Lima e Ferreira (2010), os CGR foram a grande inovação instituída pelo Pacto pela Saúde, constituindo-se enquanto instâncias de cogestão no espaço regional, pois criam um canal permanente e contínuo de negociação e decisão entre os municípios e o estado, “com regras definidas e funcionamento estável, o que possibilitará preencher aquilo que chamamos de 'vazio' de governança regional”. (VIANA; LIMA; FERREIRA, 2010, p. 2320)

De modo intrigante, percebe-se que, no processo de regionalização previsto pelo Pacto pela Saúde, há o esmaecimento do papel coordenador das equipes de APS na rede de cuidados. Apesar de todo o discurso em defesa de reformas pró-coordenação apoiadas na APS, a integração das redes regionalizadas pouco prevê mecanismos que a legitimem como coordenadora de cuidados na rede intermunicipal. Sendo assim, o profissional de APS configura-se como coordenador restrito; quando muito, ao espaço intramunicipal. Ou seja: quanto mais o município necessitar de outros entes federados para prestação de serviços de saúde, mas frágil 
será a coordenação do cuidado por equipes, comprometendo, inclusive, os atributos da APS.

\section{REDES DE ATENÇÃO À SAÚDE E O STATUS DA APS}

A organização de redes de atenção à saúde sustenta-se na necessidade de responder às demandas complexas de saúde dos brasileiros, que envolvem uma tripla carga de doenças manifestada em condições agudas - que carecem de respostas rápidas e reativas -, condições crônicas e doenças transmissíveis de curso longo, que, por sua vez, precisam de cuidados prolongados e contínuos, além de problemas relacionados à pobreza, ao estilo de vida e aos agravos decorrentes das causas externas, que necessitam de intervenções intersetoriais. (BRASIL, 2010; MENDES, 2010)

A defesa de um sistema de saúde organizado em redes justifica-se por existir um rompimento na coerência entre a situação de saúde da população, nos quesitos demográficos e epidemiológicos, e as respostas de enfrentamento apresentadas pelos modelos de atenção à saúde em escala global, que estão " [...] voltados para atenção às condições agudas e às agudizações de condições crônicas” (MENDES, 2010, p. 2299), resultando em sistemas fragmentados. Além disso, mesmo a fragmentação não pode ser compreendida como um fenômeno possível de apreensão e de natureza única, pois, na prática, apresenta-se com distintas nuances, a depender do amadurecimento político-institucional, bem como da estrutura analisada.

A necessidade de superação de problemas oriundos da fragmentação deu origem às propostas de redes de atenção à saúde, que, numa vertente mais instrumental - ou seja, na perspectiva da estrutura da organização de serviços -, ancoram-se na literatura e no debate internacional sob o manto genérico dos sistemas integrados (integrated care). Outrossim, tal perspectiva representa modelagens diversificadas que se assemelham nas estratégias utilizadas e nos arranjos organizacionais resultantes, mas que se distinguem no campo ideológico, a depender da natureza do 
sistema de proteção social (KUSCHNIR; CHORNY, 2010), e, sobretudo, dos sujeitos (stakeholders) envolvidos no contexto, que, por sua vez, desafiam toda racionalidade gerencial contemporânea. (CAMPOS, 2000, 2009, 2010a)

Por essa óptica, as redes de atenção à saúde

são organizações poliárquicas de conjuntos de serviços de saúde, vinculados entre si por uma missão única, por objetivos comuns e por uma ação cooperativa e interdependente, que permitem ofertar uma atenção contínua e integral a determinada população, coordenada pela atenção primária à saúde - prestada no tempo certo, no lugar certo, com o custo certo, com a qualidade certa e de forma humanizada -, e com responsabilidades sanitárias e econômicas por esta população. (MENDES, 2008, p. 6)

As redes de atenção à saúde podem, grosso modo, ser compreendidas segundo três elementos constitutivos: a população, a estrutura operacional e o modelo de atenção.

Para Mendes (2010), a população é o elemento central da rede; portanto, suas necessidades sociossanitárias devem ser conhecidas e mapeadas na forma de territórios sanitários (território-processo), sob a responsabilidade da APS. A estrutura operacional, segundo elemento das redes, é representada por cinco componentes: 1) APS (o centro de comunicação); 2) outros níveis de densidade tecnológica (secundário e terciário); 3) os sistemas de apoio; 4) os sistemas logísticos; e 5) o sistema de governança. Por fim, o modelo de atenção, terceiro elemento, é a racionalidade sistêmica que estampa a modelagem da rede, incidindo e sendo incidida dialeticamente nos/pelos planos político, ideológico e cognitivo-tecnológico.

Para compreensação apurada de redes de atenção, entende-se que o debate em torno da presença concreta dos sujeitos precisa estar em primeiro plano, pois são as pessoas em ato que materializam as redes de serviços de saúde, na prática cotidiana da micropolítica do trabalho em 
saúde e nos itinerários terapêuticos. Porquanto, como advertem Hartz e Contandriopoulos (2004, p. 334):

sobre a natureza do objeto 'rede', uma dupla leitura torna-se indispensável: como estrutura organizacional, voltada para a produção de serviços, e como uma dinâmica de atores em permanente renegociação de seus papéis, favorecendo novas soluções para velhos problemas num contexto de mudanças e compromissos mútuos.

O desafio de pensar redes é concebê-las como espaços de produção coletiva, no sentido de admitir que se tratam da gestão do trabalho em equipe e que, portanto, desdobram-se na produção de coisas (bens de uso) e de pessoas (rede de relações). Nessa perspectiva, pensar em redes de cuidado à saúde requer abrir-se para gestões democráticas (cogestões), o que implica algumas funções básicas:

uma clássica, de administrar e planejar processos de trabalho objetivando a produção de valores de uso; outra de caráter político, a cogestão como uma forma de alterar as relações de poder e construir a democracia em instituições; e ainda uma pedagógica e terapêutica. A capacidade que os processos de gestão têm de influir sobre a construção de sujeitos. (CAMPOS, 200o, p. 14)

O enfoque na construção de redes com serviços integrados e cuidados coordenados assenta, nas equipes de APS, o protagonismo para reorientação dos sistemas de saúde nos interstícios da rede por meio da gestão clínica. Por essa óptica, a Organização Mundial de Saúde (OMS) e a Organização Pan-Americana de Saúde (Opas) recomendam a construção de sistemas de saúde com base na APS, numa perspectiva abrangente e renovada, explicitando os valores, princípios e elementos centrais que caracterizam e justificam tal defesa. Além disso, apontam caminhos, a partir de evidências e revisão de literatura internacional, que substanciam o debate e permitem cunhar um conceito/abordagem sobre APS 
abrangente e renovada, buscando distingui-la de outras interpretações correntes. (OPAS, 2008; OPS, 2009; WHO, 2008b)

A busca por esclarecer os conceitos e abordagens para APS (Primary Health Care) sustenta-se no fato de que não há um consenso e que, portanto, existe diversidade de interpretações e concepções em sua implementação nas políticas de saúde ao redor do mundo. Fazendo-se um resgate histórico, encontra-se que a Declaração de Alma-Ata, em 1978, com o slogan "Saúde para Todos no Ano 200o" (Health for All in the Year 200o), abarcou três ideias-chave: uso de tecnologia apropriada, oposição a uma medicina elitista e a concepção de saúde como ferramenta para o desenvolvimento socioeconômico. (CUETO, 2004)

Tal compreensão apresenta uma concepção abrangente da APS, situando-a centralmente no sistema de saúde, portando atributos que a elegem enquanto estratégia para o desenvolvimento social, defendendo uma racionalidade no uso das tecnologias disponíveis e devendo ser apropriadas e socialmente aceitáveis. Além disso, advoga por uma APS de acesso universal, localizada próximo dos territórios onde vivem as pessoas, representando o primeiro ponto de contato do usuário com o sistema de saúde, aliando o conhecimento científico às práticas tradicionais, mediada pela participação da comunidade. Dessa forma, proporciona serviços de proteção, cura e reabilitação, apoiando-se em sistemas de referência integrados, conforme a necessidade das pessoas, articulando-se, ainda, com outros setores para desenvolvimento nacional e comunitário. (DECLARACIÓN..., 2002)

Segundo Tejada-de-Rivero (2003, p. 4-7), por conta da abrangência da Declaração de Alma-Ata, agências internacionais criticaram-na ao alegar que se trata de um documento pouco propositivo, impingindo releitura e ajustamento da APS bem distantes das intenções originais, com direcionamento tecnocrático "confundido como um simples conceito de programação, mais técnico que social e mais burocrático que político", além de uma "distorção entre saúde e tratamentos médicos curativos focados em poucas doenças inexplicavelmente, ainda, 
prevalentes”. Tais formulações difundiram-se, conformando uma APS seletiva (selective primary health care), direcionada a questões pontuais, centrada no binômio materno-infantil, em doenças transmissíveis e agudas, simplificação das práticas direcionadas a populações carentes, gestão centralizada, falta de integração com uma rede de cuidados, investimentos em programas verticais e práticas programáticas, restringindo-se a uma cesta de serviços básicos selecionados e de baixo custo. (CUETO, 2004; TEJADA-DE-RIVERO, 2003)

Paralelamente ao esvaziamento das ações de implementação da APS, especialmente em países em desenvolvimento, a concepção abrangente da APS, cunhada durante Alma-Ata, continuou servindo de mote para diferentes movimentos sociais, possibilitando que as lutas pela ampliação dos direitos sociais não esmaecessem. Nesse âmbito, essas ações congregaram esforços na busca do reconhecimento da saúde enquanto direito humano, mediante governos que garantissem aportes financeiros adequados e com compromisso com a justiça social. Alguns desses movimentos foram alavancados por agências internacionais, como a OMS e a Opas, no que ficou conhecido como "renovação da APS”. (GIOVANELLA; MENDONÇA, 2012) Assim sendo, entre os argumentos para renovação da APS, destacam-se os novos desafios epidemiológicos, a necessidade de correção dos pontos fracos e das inconsistências na proposta original, o desenvolvimento de novas ferramentas e novos conhecimentos, o aproveitamento das experiências acumuladas de práticas exitosas e o reconhecimento da potência transformadora da APS para superar as causas geradoras de saúde precária e iniquidade. (MACINKO et al., 2007; OPAS, 2008)

Revolvendo esse terreno conceitual, Vuori (1984) apontou quatro interpretações correntes para APS, que permanecem bastante apropriadas e atuais: APS como um conjunto de atividades; APS como um nível de atenção; APS como uma estratégia de organização dos cuidados em saúde; e APS como uma filosofia. Em um contexto mais contemporâneo, Giovanella e Mendonça (2012) e Mendes (1999) identificam três 
linhas principais de interpretação para APS, que coadunam as ideias de Vuori (1984): 1) como atenção focalizada e seletiva, com provisão restrita de serviços para grupos específicos; 2) como primeiro nível de atenção em sistemas universais, que corresponde aos serviços ambulatoriais médicos não especializados de primeiro contato, incluindo ou não amplo espectro de ações de saúde pública; 3) estratégia de reordenamento do setor saúde de forma abrangente, uma concepção de modelo assistencial e de organização do sistema de saúde, para toda a sociedade.

Uma APS como cesta básica de serviços caracteriza as experiências, de modo geral, nos países em desenvolvimento, enquanto que, na Europa, a APS refere-se, grosso modo, aos serviços de primeiro contato, integrados a uma rede de serviços. Dessa forma, funciona como porta de entrada obrigatória (gatekeeping) e centrada em práticas médicas (general practioners - GP), correspondendo a serviços ambulatoriais não especializados e enfatizando a clínica e os cuidados individuais. Portanto, “[...] não contempla alguns aspectos da concepção abrangente da APS, mais voltada aos problemas coletivos, à atuação intersetorial e à participação social nos serviços de saúde". (GIOVANELLA; MENDONÇA, 2012, p. 508)

No percurso desse debate, torna-se crucial e complexo identificar quais elementos definem uma APS abrangente, bem como reconhecer quais os requisitos fundamentais para que a APS seja eleita como estratégia prioritária nas políticas de saúde. Enfim, se existem aspectos que podem ser captados acerca da natureza da APS ou quais fenômenos são desdobramentos da existência de sistemas de saúde alicerçados na APS. Assim, Starfield (2002) pondera que, mesmo a APS oferecendo o suporte filosófico para a organização de um sistema de serviços de saúde, as definições gerais são insuficientes para avaliar se um dado sistema merece a descrição de APS, requerendo, para tanto, maior especificidade dos pesquisadores para o estabelecimento de metas e aperfeiçoamento contínuo em sua realização. 
Trilhando por essa seara, Starfield (2002) realizou uma extensa revisão acerca das tentativas de inúmeros estudos para definir uma abordagem para medição (capacidade e desempenho) da APS de alta qualidade no contexto dos sistemas de saúde. A autora desenvolveu, a partir de avaliações em países desenvolvidos, uma definição para a APS sustentada por meio de funções que, combinadas, são peculiares à APS: serviço de primeiro contato centrado na pessoa e não na enfermidade; cuidado ao longo do tempo; atenção a todos os casos; e coordenação e integração à atenção provida por outros parceiros do sistema (quando a APS não pode resolver). Destacou, ainda, outras características que a APS compartilha com os demais níveis do sistema, mas que, ainda que imprescindíveis à APS, não são distintivas: responsabilidade pelo acesso, qualidade e custos; atenção à prevenção, tratamento e reabilitação; e trabalho em equipe. Declara, também, que a APS “é a atenção que organiza e racionaliza o uso de todos os recursos, tanto básicos como especializados, direcionados para promoção, manutenção e melhora da saúde”. (STARFIELD, 2002, p. 28)

A partir dos esforços de Starfield (2002), inúmeros autores têm buscado delimitar os atributos essenciais da APS e refinar as pesquisas avaliativas, apostando nos seguintes componentes: ponto de primeiro contato dentro do sistema de atenção à saúde (first contact/gatekeeper), longitudinalidade, vínculo e continuidade relacional do cuidado (longitudinality), abrangência e integralidade (comprehensiveness), coordenação do cuidado com serviços integrados (coordination), orientação para a comunidade, centralidade na família (family and/or community orientation) e competência cultural. (GIOVANELLA; MENDONÇA, 2012; MACINKO; STARFIELD; SHI, 2003) Outras contribuições têm agregado novos elementos à proposta original por meio de pesquisa para adaptar, validar e aplicar uma Ferramenta de Avaliação da APS (Primary Care Assessment Tool - PCAT), acrescentando a acessibilidade e formação profissional entre as suas dimensões essenciais (MACINKO; ALMEIDA; OLIVEIRA, 2003); aplicação do PCAT na avaliação da 
produção do cuidado em diferentes cidades na Bahia, agregando acesso, acolhimento e resolubilidade entre as dimensões de análise dos atributos da APS (ASSIS et al., 2010), e revisão sistemática das dimensões centrais da APS, desvelando seus atributos na estrutura - governança, condições econômicas e formação das equipes de trabalho no processo -, acesso, continuidade, coordenação e integralidade e nos resultados - qualidade, eficiência e equidade na saúde, definindo a APS enquanto sistema multidimensional. (KRINGOS et al., 2010)

Retomando o enfoque inicial, percebe-se que o debate em torno das redes de atenção à saúde centraliza o status da APS como articuladora entre os diferentes componentes do sistema, sem explicitar como se daria essa função. Mendes (2010), por exemplo, destaca a APS como componente-chave na organização das redes de atenção à saúde, colocando-a como o centro de comunicação. Sendo assim, cabe à equipe de APS coordenar os fluxos e contrafluxos do sistema, ser resolutiva - solução de $85 \%$ dos problemas da população, acolher e responsabilizar-se pelas demandas da população -, com potência para coordenar o cuidado continuado, por meio do encadeamento adequado dos demais componentes da rede.

Tal incumbência e status delegados à APS requerem a mobilização dos seus atributos simultaneamente para darem conta de responder ao complexo desafio da gestão do cuidado em uma rede regionalizada de atenção à saúde. Além disso, as redes de atenção à saúde, no Brasil, têm peculiaridades oriundas da configuração institucional do SUS - estrutura decisória e de gestão -, da base de financiamento, além das singularidades da APS no país e das concepções teóricas acerca dos seus atributos, colocando essa questão muito mais no campo do desejo do que em uma realidade consubstanciada na prática.

Esses pontos foram levantados também por Testa (1992), quando afirma não ser possível considerar a APS como um conceito totalizante, pois é dependente do contexto do sistema de saúde em que está inserida. Nesse sentido, a APS deve ser a porta de entrada do sistema de saúde, 
resolvendo os problemas possíveis e orientando os demais para outros níveis.

isso implica uma rede de estabelecimentos interligados por claros procedimentos de referência e de transmissão da informação pertinente, que ordenam a circulação interna dos pacientes no sistema; também implica um ordenamento territorial regionalizado e um comportamento social que obedeça, mais ou menos disciplinarmente, às normas de ingresso e circulação. (TESTA, 1992, p. 161)

Esse autor alerta que países que não lograram atrelar a APS a uma rede regionalizada produziram uma atenção "primitiva" de saúde, com serviços de segunda categoria, constrangendo o direito de cidadania.

Em 2009, o documento Redes Integradas de Servicios de Salud basadas en La Atención Primaria de Salud (OPS, 2009), resultado de consultas em países da América Latina e Caribe realizadas pela Opas, abordou a problemática da fragmentação dos sistemas de saúde, bem como validou a proposta da Opas de Redes Integradas de Serviços de Saúde nas Américas.

Por sua vez, ainda que reconheça a diversidade de contextos entre os diferentes países e a necessidade de adaptação das propostas às questões locorregionais, a partir de evidências, a Opas apontou 13 atributos essenciais, ainda que genéricos, ao funcionamento adequado das redes de atenção à saúde:

1. territorialização e adscrição, com amplo conhecimento das necessidades e preferências da população;

2. rede de estabelecimentos de saúde extensa, diversificada (distintas densidades tecnológicas) e integrada, capaz de atender as diferentes demandas sociais de saúde;

3. APS atuando como porta de entrada do sistema, composta por equipe multidisciplinar, integrando e coordenando a atenção à saúde e satisfazendo a maior parte das necessidades de saúde; 
4. serviços especializados ofertados em local adequado;

5. existência de coordenação dos cuidados longitudinalmente;

6. atenção à saúde centrada na pessoa, família e comunidade, atenta às singularidades e à diversidade da população;

7. sistema de governança única para toda a rede;

8. ampla participação social;

9. gestão integrada dos sistemas de apoio administrativo, clínico e logístico;

10. política de gestão do trabalho em saúde para a rede;

11. sistema de informação integrado e compartilhado;

12. financiamento adequado; e

13. ação intersetorial e equidade.

Tais argumentos conclamam por uma análise acerca da estratégia de gestão do cuidado em redes de atenção à saúde no Brasil. No cenário nacional, discutir gestão de redes de atenção à saúde requer refletir o modelo de proteção social que se deseja e que se está disposto a construir. (CAMPOS, 2007) Sendo assim, há um componente ideológico para além dos componentes técnico-metodológicos, ou seja, reconhecem-se os elementos estruturantes para existência da rede, mas questionam-se os desdobramentos a partir dos sujeitos concretos que a materializam na prática social.

\section{APS COMO COORDENADORA DO CUIDADO NAS REDES DE ATENÇÃO À SAÚDE NO BRASIL}

A APS, no Brasil, é denominada correntemente, na literatura e nos documentos oficiais, como Atenção Básica à Saúde (ABS). A justificativa para a adaptação do termo deveu-se à tentativa de afastamento das práticas em APS seletivas apoiadas por agências internacionais e disseminadas nos países em desenvolvimento ou com enfoque centrado em procedimentos 
médicos (comuns à Europa). (GIOVANELLA, 2008; GIOVANELLA; ESCOREL; MENDONÇA, 2009) No primeiro momento, a ABS,

[...] além de referir apenas o primeiro nível sem apontar a integração ao sistema de saúde, não implicava em um modelo assistencial diferenciado, [mantendo-se a atenção calcada, muitas vezes, apenas] na resposta ao pronto-atendimento da demanda espontânea ou baseada nos tradicionais programas de saúde pública dos centros de saúde. (GIOVANELLA; ESCOREL; MENDONÇA, 2009, p. II)

Nesse sentido, a distinção semântica não logrou mudanças das práticas, sobretudo na primeira década de implementação do SUS, período que foi marcado por forte tensão das políticas sociais restritivas de caráter neoliberal. Tais questões deflagraram disputas acirradas entre um projeto de construção da universalidade tendo a saúde como direito de cidadania e, de outro lado, o princípio da contenção de gastos e da racionalidade econômica. (MENDES; MARQUES, 2009)

Destarte, sob o manto do Programa Saúde da Família (PSF), criado em 1994, o Ministério da Saúde sustenta a retórica de reversão de um modelo de atenção fragmentado, ineficiente e reprodutor de iniquidades. Mas, na prática, convive-se lado a lado com uma Atenção Básica que se apresenta como política focalizada e seletiva, para demandas de grupos específicos, e universalista, enquanto direito de todo cidadão (VIANA; FAUSTO, 2005), cumprindo parcialmente sua agenda. (SOUSA; HAMANN, 2009)

Por outro lado, em 2006, a Política Nacional de Atenção Básica (PNAB) renova o discurso e reitera a Saúde da Família como estratégia prioritária para consolidação da Atenção Básica em todo país. A PNAB, atualizada pela Portaria no 2.488, de 21 de outubro de 2011 (BRASIL, 2012a), abarca as características da ABS, consolidando seu aspecto abrangente e prioritário, afastando-se "completamente" de qualquer sombra de seletividade ou cesta de serviços para grupos específicos, além de explicitar o papel desejado da Atenção Básica nas redes de atenção à saúde. Por essa óptica, o documento ressalta que a Atenção Básica 
utiliza tecnologias de cuidado complexas e variadas que devem auxiliar no manejo das demandas e necessidades de saúde de maior frequência e relevância em seu território, observando critérios de risco, vulnerabilidade, resiliência e o imperativo ético de que toda demanda, necessidade de saúde ou sofrimento devem ser acolhidos. (BRASIL, 2012a, p. 19)

Tais elementos fertilizam diferentes posicionamentos, mesmo no interior da Saúde Coletiva, e evidenciam os desafios da Atenção Básica e a estratégia de implementação por meio da ESF. Nessa seara, Campos (2008) e Cohn (2008), em debate com um artigo de Conill (2008), assinalam que o "vazio programático para a questão assistencial no SUS" (CONILL, 2008, p. 11) expõe o esmaecimento do debate político em torno dessa questão, colocando-a como um consenso, como um debate definido, cabendo apenas colocar em prática e avaliar tudo que está previsto nas normas ministeriais.

Para Campos (2008), o governo federal não encara os grandes problemas que minam o avanço do PSF - financiamento, formação de pessoal e gestão do trabalho, por exemplo -, circundando esses problemas com propostas paliativas, uma vez que

não há evidências de que o Ministério da Saúde esteja disposto a assumir a articulação dessa multiplicidade de experiências e de entidades federadas para construir um sistema - rede interdependente, apesar da autonomia dos municípios - que combine singularidade local com diretrizes que assegurem unidade ao SUS. (CAMPOS, 2008, p. 19)

Por sua vez, Cohn (2008) acirra essa discussão colocando que, sem renovação do debate acadêmico e outras perspectivas na agenda política, incorre-se no perigo de que

[...] ao se assumir o PSF como uma estratégia de mudança do modelo assistencial brasileiro, esvazia-se, paradoxalmente, a dimensão da política e tende a tomar seu lugar a dimensão técnica 
na busca de avaliação, monitoramento e aperfeiçoamento desse modelo. (COHN, 2008, p. 24)

A própria autora retoma essa discussão e demarca que há poucos estudos críticos que questionam o já estabelecido, pois

qualquer passo desmedido no sentido da crítica do já instituído, ou do que vem sendo instituído, é interpretado quase que imediatamente como oposição ao SUS e, portanto, como algo condenável, política e moralmente. (COHN, 2009, p. 9)

Não obstante, independente da vertente, constata-se que a ESF expandiu-se por todo país, sob fomento do Ministério da Saúde, tornando-se a principal política de saúde com enfoque nos cuidados de primeiro nível. Apresenta, em estudos empíricos, além dos desafios, possibilidades animadoras a sua assunção. (ASSIS et al., 2010; CAMARGO JR. et al., 2008; ELIAS et al., 2006; FACCHINI et al., 2006; GIOVANELLA et al., 2009; IBAÑEZ et al., 2006)

A pertinência da exposição de dissonâncias e convergências em torno da ESF aponta para necessidade de trilhar por caminhos que questionem a potência da APS brasileira, porquanto "a rede de saúde da família vem sendo criada de maneira desarticulada com o restante do sistema, havendo pouca relação entre atenção primária e especialidades ou hospitais”. (CAMPOS, 2007, p. 304)

No contexto de uma rede regionalizada, as dimensões para a gestão do cuidado reclamam por uma análise para dentro do município e para além das suas fronteiras, numa perspectiva de rede integrada, em uma conformação cooperada e solidária, para garantir maior organicidade e racionalidade ao sistema de saúde, de modo a efetivar o papel dos profissionais da APS como coordenadores do cuidado.

Por outra via, as características da APS no Brasil suscitam questões, somadas às apontadas em estudos sobre os sistemas de saúde internacionais, que tensionam a gestão do cuidado em rede: 
1. A equipe de atenção primária no Brasil, compreendida como ESF, é formada por diferentes trabalhadores - nível superior e médio - que devem exercer o cuidado à saúde em equipes multiprofissionais e práticas interdisciplinares (CAMPOS, 2003; SOUSA; HAMANN, 2009);

2. A porta de entrada é difusa, notadamente onde a APS tem baixa cobertura, geralmente nos grandes centros urbanos onde vivem a maioria dos brasileiros -, resultando em baixa coordenação e competição com os estabelecimentos de pronto-atendimento e os hospitais públicos e privados (BRASIL, 2005; CAMPOS, 2008; VIANA et al., 2008);

3. A inscrição dos usuários no serviço de APS está atrelada ao local de residência e é compulsória (GIOVANELLA, 2006), com adscrição média de 3 mil pessoas por equipe (BRASIL, 2012a);

4. Os profissionais da APS devem atender a todos os grupos e a um amplo espectro de problemas, executando ações promocionais, preventivas, curativas e reabilitadoras (BRASIL, 2012a; CAMPOS, 2003);

5. A provisão e o financiamento dos serviços de APS são públicos e de acesso universal (GIOVANELLA; MENDONÇA, 2012);

6. A forma de pagamento dos trabalhadores é o assalariamento, com uma diversidade de modalidade de vínculo e complexos problemas na política de gestão do trabalho (ASSIS et al., 2008; MENDONÇA et al., 2010);

7. A APS é de responsabilidade do ente municipal (MENDES, 2002), mas os demais serviços da rede - média e alta densidade tecnológica - podem ter distintos provedores e diferentes naturezas jurídicas (NORONHA; LIMA; MACHADO, 2008);

8. A cobertura da APS é insuficiente e limitada a determinados dias e horários, restringindo seu papel de porta de entrada preferencial (CECÍLIO, 1997; MATTOS, 2009b);

9. Muitos profissionais não têm formação adequada para trabalhar na APS e o especialista é socialmente mais valorizado que 
o profissional generalista, situação que se reproduz entre os gestores (CAMPOS et al., 2008; MENDES, 2002);

10. Persistem problemas na infraestrutura das unidades de saúde e deficiência no aporte de medicamentos essenciais, apoio diagnóstico e consultas complementares (MENDES, 2002);

11. A maioria dos municípios brasileiros - cerca de $90 \%$ - tem menos de 50 mil habitantes e sua rede de serviços resume-se, muitas vezes, à APS (NORONHA; LIMA; MACHADO, 2008);

12. A coordenação do cuidado na rede a partir da APS - quando existe-limita-se ao município, tendo que submeter a demanda por cuidados "especializados" às regras de oferta pactuadas entre os gestores municipais e estaduais, quando se necessita de ações de outros níveis não contempladas no próprio município, com preocupantes problemas na regulação dos fluxos entre os serviços. (MAGALHÃES JÚNIOR; OLIVEIRA, 2006)

Assim, buscando propostas que orientem a construção de sistemas de serviços integrados e cuidados coordenados por equipes de APS, tomando como cenário o SUS, Silva (2008) propõe, ainda que genericamente, o aperfeiçoamento das redes regionalizadas de atenção à saúde mediante fortalecimento da APS, organização da rede via APS, fortalecimento da regulação e da gestão regional:

1. Fortalecimento da APS - reafirmar o conceito abrangente, adequar a oferta e a formação dos profissionais, organizar o processo de trabalho no espaço do território, ampliação do escopo e apoio matricial;

2. Organização da rede de atenção via APS - análise da situação de saúde e da rede existente na região, desenho da rede mais adequada à região, identificação dos problemas e análise de cenários, elaboração de plano de ação para aperfeiçoar a rede regional;

3. Fortalecimento da regulação - identificação dos usuários e cadastramento dos estabelecimentos e profissionais da região, avaliação e readequação dos instrumentos que regulam 
a oferta assistencial na região, legitimação ou criação de protocolos técnico-assistenciais, criação ou adequação do suporte logístico;

4. Fortalecimento da gestão regional - fortalecer a governabilidade e ampliar a governança.

\section{INTEGRAÇÃO ASSISTENCIAL E COORDENAÇÃO DO CUIDADO: CONTRIBUIÇÕES PARA PENSAR A GESTÃO EM REDES REGIONALIZADAS DE ATENÇÃO À SAÚDE}

Os conceitos de integração e coordenação em saúde representam abstrações teóricas para designar a natureza de modos de organização dos sistemas, serviços e dos cuidados em saúde. Contudo, a definição acerca da integração e coordenação permanece difusa na literatura, ora sobrepondo-se com o mesmo sentido, ora apresentando-se como conceitos complementares e, em algumas situações, enquanto termos que podem existir independentes um do outro. Por esse prisma, percebe-se que tanto "integração" quanto "coordenação" podem denotar situações diversas, a depender do contexto e dos sujeitos que as empregam.

O debate em torno da integração e da coordenação não é novo (MUR-VEEMAN; VAN RAAK; PAULUS, 2008), porém reacende sua importância ante os problemas não superados - iniquidades e ineficiência - nos sistemas de saúde latino-americanos (CONILL; FAUSTO; GIOVANELLA, 2010; VÁZQUEZ et al., 2009) e novos desafios como o impacto da crise financeira e as medidas de austeridade que incidem nos sistemas de saúde europeus. (MLADOVSKY et al., 2012; WHO, 2009) Por conseguinte, trata-se de um tema que recebe ampla atenção nos países da Organização para Cooperação e Desenvolvimento Econômico (OCDE), na Opas, no Observatório Europeu em Sistemas e Políticas de Saúde e, mais recentemente, ganha espaço na agenda das pesquisas realizadas no Brasil. 
Entre os argumentos em defesa da integração e coordenação para organizações dos sistemas de serviços de saúde, destacam-se as necessidades de reduzir a segmentação e fragmentação da atenção, de garantir a equidade no acesso, de aumentar a eficiência e a qualidade dos serviços de saúde (CONILL; FAUSTO; GIOVANELLA, 2010; VÁZQUEZ et al., 2009), de evitar a sobreposição desnecessária, onerosa e iatrogênica em intervenções médicas, de direcionar os serviços e de distribuir os profissionais adequadamente entre os diferentes níveis. (SALTMAN; RICO; BOERMA, 2006) Não obstante, destacam-se também: possibilitar a gestão clínica e a continuidade do cuidado das condições crônicas, reduzindo a hospitalização desnecessária, buscando uma atenção balanceada, com adequação da oferta de serviço e organização dos fluxos entre serviços especializados de média e alta densidade tecnológica e a atenção de primeiro nível (GIOVANELLA, 2011; GREß et al., 2009), controlar os custos (LEATT; PINK; GUERRIERE, 20oo), além de favorecer o fluxo comunicacional, atenção ao longo do tempo e a continuidade do cuidado. (HAGGERTY et al., 2003)

Ressalta-se, também, que os termos "coordenação", "continuidade" e "integração assistencial” são utilizados, muitas vezes, indistintamente para referir-se a uma mesma ideia. Entretanto, para Opas, há matizes importantes que diferenciam tais conceitos. Assim, a continuidade retrataria melhor a relação entre usuário e provedor, que, por sua vez, para existir, necessitaria de coordenação na atenção e, finalmente, a integração corresponderia a um nível avançado de coordenação. (OPS, 2008)

Em diversos países da América Latina - entre eles, Colômbia, Chile e Brasil -, a integração dos serviços de saúde (integrated health care networks, integrated health care delivery systems ou health systems integration), mesmo com trajetórias e opções políticas distintas, tem sido um meio para as reformas em curso no setor, sendo uma estratégia para melhorar a eficiência e o acesso aos cuidados em saúde. (VÁZQUEZ et al., 2009) Esses autores apresentam cinco características principais das redes integradas de serviços de saúde: 
1. A diversidade de problemas de saúde deve encontrar respostas e estes devem ser resolvidos dentro da rede de serviços;

2. O sistema deve evitar sobreposição entre os níveis;

3. O primeiro nível de atenção deve atuar como entrada preferencial para toda a rede (gatekeeping);

4. Disponibilidade de informação clínica do usuário deve estar acessível em todos os pontos da rede (referência e contrarreferência ou prontuários eletrônicos compartilhados); e

5. As várias tecnologias devem ser distribuídas (centralizadas ou descentralizadas) apropriadamente entre os distintos pontos e níveis da rede, atentando para efetividade e eficiência.

Também no âmbito de sistemas de saúde latino-americanos, Conill e Fausto (2007), em análise comparada para analisar a problemática da integração, concluem que, embora haja inúmeras diferenças na implementação dos sistemas de serviços de saúde entre os países estudados, há uma política continental - proposta e defendida pela Opas - para a renovação e fortalecimento da APS, visando a integração e coordenação entre os níveis. Os resultados identificaram três modalidades de integração:

1. Atenção primária seletiva (Bolívia, Nicarágua e El Salvador) no interior de programas materno-infantis (coordenação restrita e integração focalizada);

2. Experiências municipais em sistemas baseados em seguros (iniciativas isoladas, na Colômbia); e

3. APS como porta de entrada (Brasil, Costa Rica, Chile e Venezuela) e eixo estruturante de um sistema público (política de reorganização do modelo assistencial).

A terceira modalidade, comum a sistemas universais, apresentou uma série de estratégias importantes para fortalecimento de redes integradas de saúde: territorialização com adscrição de clientela, equipes multidisciplinares, informatização de prontuários, centrais de marcação de consultas, equipes especializadas de apoio, consórcios para atenção 
especializada, comitês de integração de serviços, criação de redes e estímulo à gestão regional. (CONILL; FAUSTO; GIOVANELLA, 2010) Contudo, segundo tais autoras, mesmo nos países com sistemas universais, havia persistência de segmentação com fragmentação dos serviços, forjando integração e coordenação frágeis entre os níveis de atenção. Essa conclusão também é evidenciada em pesquisa que compara a política de atenção integrada (integrated care policy) em seis países europeus. (MUR-VEEMAN; VAN RAAK; PAULUS, 2008)

A integração dos serviços de saúde é a contraposição aos modelos fragmentados, ou seja, é a busca por consubstanciar uma organicidade aos sistemas de saúde que se sustenta em três eixos:

a oferta de serviço, de forma contínua, por meio de vários pontos de atenção à saúde; a integração desses pontos de atenção à saúde, por meio de um sistema de gestão da clínica, e a existência de uma população adscrita, cuja saúde é de responsabilidade inequívoca do sistema. (MENDES, 2001, p. 72)

Percebe-se que, na concepção do autor, os pontos centrais da integração do sistema de saúde modelam uma rede de atenção à saúde.

Em extensa revisão sistemática de literatura sobre integração de sistemas de saúde (health systems integration), Armitage e colaboradores (2009) afirmam que, apesar do grande número de artigos que discutem a integração, persiste uma insuficiência de estudos empíricos de alta qualidade que forneçam evidências para tomada de decisão. Os autores percebem, ainda, a ausência de um conceito ou definição universal para a integração e apontam a falta de ferramentas validadas e padronizadas para avaliação dos resultados, o que torna a tarefa de medir e comparar o impacto da integração no nível das práticas, serviços e sistema de saúde um grande desafio para gestores e pesquisadores.

Mesmo considerando que não seja possível um modelo como "receita única para qualquer contexto” (one-size-fits-all) para integração, Suter e colaboradores (2009) identificam um conjunto de dez princípios 
universais na literatura revisada, que são essenciais e presentes em sistemas de saúde integrados bem-sucedidos. Trata-se de princípios genéricos, mas que permitem, segundo esses autores, uma avaliação dos esforços realizados para integração em sistemas de saúde, pois definem áreas essenciais e permitem flexibilidade e adaptação aos diferentes contextos:

1. serviços integrais e atenção contínua (comprehensive services across the continuum of care);

2. serviços centrados no usuário (patient focus);

3. cobertura e adscrição populacional (geographic coverage and rostering);

4. padronização dos cuidados entre as equipes de saúde nos diferentes níveis (standardized care delivery through interprofessional teams);

5. gestão por desempenho (performance management);

6. sistemas de informação (information systems);

7. liderança e cultura organizacional (organizational culture and leardship);

8. integração entre os médico de diferentes níveis do sistema (physician integration);

9. estrutura de governança (governance structure); e

10. gestão financeira (financial management).

Com efeito, a necessidade de integração tem desafiado as reformas dos sistemas de saúde em todo o mundo. Na Europa, muitos países introduziram mecanismos para melhorar a integração do sistema hospitalar, porém utilizando-se de abordagens com diferentes termos como: shared care, transmural care, intermediate care, seamless care, disease management, case management, continuous care, integrated care pathways and integrated delivery networks. (GRÖNE; GARCIA-BARBERO, 2001) Para esses autores, embora tenham o objetivo comum de melhorar a integração e coordenação dos serviços, tais abordagens têm abrangência 
e metas bastante diferentes: alguns focando, sobretudo, na redução de custos e outros que procuram melhorar a qualidade, o acesso e a satisfação dos usuários. Por sua vez, sustentam a definição de atenção integrada (integrated care), adotada pela OMS europeia (WHO European Office for Integrated Health Care Services), como

um conceito que junta insumos, gestão e organização dos serviços relacionados ao diagnóstico, ao tratamento, ao cuidado, à reabilitação e à promoção da saúde. A atenção integrada é um meio para melhorar os serviços em relação ao acesso, qualidade, satisfação do usuário e eficiência. (GRÖNE; GARCIABARBERO, 2001, p. 7, tradução nossa)

Tais borramentos teóricos foram investigados pela OMS, que, entendendo a dispersão dos conceitos, sintetizou os "serviços integrados de saúde" (integrated health services) em seis modalidades mais correntes:

1. como um amplo conjunto de intervenções preventivas e curativas para um determinado grupo populacional;

2. como pontos de distribuição de serviços multiuso;

3. enquanto continuidade da atenção ao longo do tempo;

4. como integração vertical de diferentes níveis de serviço;

5. como vinculação entre a formulação de políticas e gestão dos serviços;

6. na qualidade de trabalho intersetorial.

Por fim, cunha uma definição preliminar sobre integração, admitindo tratar-se "da gestão e distribuição de serviços de saúde de forma que as pessoas recebam um conjunto de serviços preventivos e curativos, de acordo com suas necessidades ao longo do tempo e por meio de diferentes níveis do sistema de saúde”. (WHO, 2008a, p. 4, tradução nossa)

Ao sintetizar características de uma atenção integrada (integrated healthcare) de saúde no sistema canadense, Leatt, Pink e Guerriere (200o) listam alguns critérios que os serviços devem ter/ser para o 
usuário: o usuário não precisa repetir sua história a cada atendimento; não precisa se submeter a repetições de exames a cada nova consulta; o usuário não é a única fonte de informação para que o médico ou outro profissional conheça a sua história de utilização de serviços, procedimentos e medicamentos; o usuário não se submete a um nível de atenção inadequado por incapacidade de atendimento em outro nível; dispõe de 24 horas de acesso a um estabelecimento ligado à atenção primária; recebe informação clara e precisa sobre a qualidade da assistência e resultados esperados das opções terapêuticas, permitindo-lhe fazer escolhas esclarecidas; pode marcar uma consulta ou receber um resultado por telefone; tem opções de escolha para consultas na APS e os profissionais devem dispor de tempo suficiente nas consultas de primeiro nível; é rotineiramente contatado para prevenir complicações de problemas crônicos; recebe informações sobre sua doença, apoio domiciliar e em autocuidado que maximize a sua autonomia.

Ainda no campo conceitual, uma distinção importante é feita por Rosen e colaboradores (2011) entre "integração" (integration) e "atenção integrada" (integrated care). Segundo esses pesquisadores, integração é um conjunto de métodos, processos e ferramentas de suporte para coordenação de serviços de atenção à saúde. Por sua vez, atenção integrada refere-se ao produto final da integração em termos de serviços - centrado no usuário - para cumprir requisitos de alta qualidade, custo-eficiência e altos níveis de satisfações dos usuários. Ou seja, a atenção integrada pode ser caracterizada pela coerência e coordenação na prestação de serviços de saúde para as pessoas, por meio de uma ampla gama de organizações de atenção à saúde, diferentes profissionais e cuidadores informais.

Entretanto, o cotejamento entre sistemas de serviços europeus Áustria, Espanha, Finlândia, Holanda, Inglaterra e Suécia - revelou que, mesmo com sistemas consolidados, apresentam diferentes graus de fragmentação, sendo que as políticas de atenção integrada são engendradas para atender a determinados agravos crônicos ou grupos específicos - idosos, deficientesm - e com relativa insuficiência na coordenação 
pelos médicos de APS. (MUR-VEEMAN; VAN RAAK; PAULUS, 2008) É importante sublinhar que os autores se referem a modelos de cuidados médicos, típicos de países que fazem uma distinção entre serviços clínicos e serviços de saúde pública, com papel periférico de outros profissionais -inclusive enfermeiros -, restringindo a integração aos cuidados individuais, pois outras políticas sociais - educação, saneamento básico, transporte, habitação etc. - já estão consolidadas e universalizadas.

Ainda na perspectiva internacional sobre as origens e matrizes dos sistemas integrados, há inúmeras experiências, com distintas abordagens, oriundas do setor público ou privado, sendo o movimento universal de desospitalização, a viragem ambulatorial canadense, a substituição europeia e a atenção gerenciada americana as mais significativas. (MENDES, 2001)

Uma leitura atenta dos diversos livros e textos produzidos por Mendes (1999, 2001, 2002, 2007, 2008, 2010, 2011) revela que o autor, após inúmeras revisões de literatura e incursões teóricas e práticas, parte da concepção inicial de sistemas integrados de saúde para uma de redes de atenção à saúde. Ao analisar as redes nos últimos anos, a integração passa a ser um atributo interno à sua materialização. Para esse autor, a integração pode ser horizontal - por semelhança ou coincidência na função - ou vertical - por diferenças de funções e necessidade de complementaridade -, mas deve superar a ideia hierarquizada e piramidal, atribuindo à APS o status de coordenadora dos cuidados. E, nessa órbita, "a coordenação, a articulação de diferentes partes em relações apropriadas para assegurar a efetividade, é diferente da integração, a combinação das partes formando um todo". (MENDES, 2007, p. 16)

A integração dos serviços de saúde tende a atuar de maneira equilibrada sobre as condições agudas e crônicas, desde que estejam organizados por um conjunto coordenado de pontos de atenção à saúde em formato de redes de atenção à saúde. (MENDES, 2011) Na via contrária, a fragmentação causa baixo desempenho aos sistemas de saúde, por conta da dificuldade de acesso aos serviços, perda da continuidade 
dos processos assistenciais, incoerência entre necessidade e oferta de serviços, uso inadequado e ineficiente dos recursos disponíveis, incremento desnecessário dos gastos e baixa satisfação dos usuários. Por consequência, evidenciam-se demanda reprimida e atrasos na oferta de serviços, repetições desnecessárias e perda de histórias clínicas, duplicações de provas diagnósticas, ações voltadas para condições agudas ou eventos agudos das condições crônicas, médico especialista assumindo definitivamente o cuidado do usuário, ao invés de assumir a condição de interlocutor com a APS. (MENDES, 2011; OPS, 2008) Em síntese, a fragmentação manifesta-se, fundamentalmente,

como falta de coordenação e intercomunicação entre os distintos pontos de atenção, duplicação de serviços e infraestrutura, capacidade instalada ociosa em alguns casos ou utilização excessiva em outros, cuidado de saúde fornecido em lugar menos apropriado, particularmente em hospitais, e distribuição inadequada dos pontos de serviços de saúde. (OPS, 2008, p. 12, tradução nossa)

Para superar a fragmentação em sistemas de saúde, a interface entre integração e coordenação é indissociável e indispensável. Por esse prisma, Vázquez e colaboradores (2009) apresentam um quadro conceitual para análise do desempenho dos sistemas integrados de saúde, tomando como alicerce uma extensa revisão sistemática. De acordo com esses autores, os resultados de sistemas integrados de saúde consolidados apresentam um nível intermediário, correspondendo à coordenação, continuidade do cuidado e acesso. Por sua vez, satisfeito esse nível, o resultado final seria maior equidade no acesso e melhor eficiência na rede de serviços.

Em síntese, a integração pode ser considerada o mais alto grau de coordenação (VÁZQUEZ et al., 2009), assim como a coordenação é entendida como uma conexão harmoniosa de diferentes serviços, necessários para prover cuidado continuado das pessoas, articulados, numa rede integrada, para resolver as necessidades dos usuários. Em contrapartida, a 
continuidade relaciona-se ao modo como os usuários percebem e vivenciam a coordenação e a integração nos serviços.

No debate atual, nos sistemas europeus, os estudos de Greß e colaboradores (2009), Gérvas e Rico (2005), Saltman, Rico e Boerma (2006), além de Wadmann, Strandberg-Larsen e Vrangbek (2009), defendem que os sistemas integrados de saúde devem apoiar-se na APS como coordenadora dos cuidados - reformas pró-coordenação - para atingir alguns objetivos básicos, como o cuidado continuado, a longitudinalidade, a resolubilidade dos problemas no nível mais adequado, melhora progressiva dos resultados, equidade e uso adequado dos recursos.

Nada obstante, Giovanella (2006) adverte que o movimento de reformas pró-coordenação nos sistemas de saúde europeus ocorre num contexto de restrição de gastos, buscando um melhor desempenho custo-efetivo, aumento da qualidade e eficiência, mas que, ainda assim, respondeu a mudanças do perfil epidemiológico - envelhecimento e doenças crônicas -, novos métodos terapêuticos e de diagnóstico e necessidade de cooperação interorganizacional entre os níveis de atenção. Para tanto, as reformas seguiram dois caminhos: 1) aumento do poder e controle da APS sobre os prestadores de outros níveis, fortalecendo a coordenação; e/ou 2) expansão da oferta de serviços e funções da APS, privilegiando a provisão. O principal mecanismo para aumentar o poder da APS foi adotá-la como porta de entrada obrigatória (gatekeeping), sobretudo nos países com sistema nacionais de saúde. Por sua vez, o principal dispositivo utilizado para aumentar o escopo da APS foi ampliar as funções dos médicos generalistas seguindo diretrizes clínicas ou criando novos arranjos de trabalho para a APS, como:

contratação de especialistas em tempo parcial para trabalho em centros de saúde junto com generalistas, integração com serviços de enfermagem e de saúde mental, cooperativas de generalistas para prestar pronto-atendimento fora do horário comercial, e realização de procedimentos especializados pelos próprios 
generalistas que se tornam referência interna para determinado grupo de generalistas. (GIOVANELLA, 2006, p. 959)

A viabilidade e pertinência de sistemas coordenados e direcionados pela APS, na Europa, não são uma resposta inequívoca, devido à diversidade de sistemas de saúde e às características na sua condução nos distintos países da União Europeia. (BOERMA, 2006) Apesar disso, temas comuns - como o envelhecimento populacional, a crescente necessidade de enfrentamento das condições crônicas, as comorbidades, as novas modalidades de diagnóstico e terapia, a crescente especialização e subespecialização dos profissionais, a demanda por cuidados continuados e os custos na área da saúde - têm exposto a ineficiência dos sistemas fragmentados e descoordenados para lidar com tais questões. (BOERMA, 2006; CALNAN; HUTTEN; TILJAK, 2006; MUR-VEEMAN; VAN RAAK; PAULUS, 2008)

Nesse sentido, Greß e colaboradores (2009) realizaram estudos de caso comparando oito países europeus e, como resultados, perceberam que nações com um sistema de APS forte - Espanha, Finlândia, Holanda, Inglaterra e País de Gales - tendiam a desenvolver melhor integração entre os níveis, potencializando a gestão e coordenação das condições crônicas, em contraste com países com APS fraca - Áustria, Bélgica e Alemanha -, cujo sistema mostrou-se desarticulado e com dificuldades na coordenação.

As principais dificuldades para coordenação de serviços de saúde ocorrem pela "assimetria da informação". Além disso, as decisões médicas são difíceis de serem julgadas e os resultados sanitários não são fáceis de medir, pois nem sempre são imediatos e não estão atrelados unicamente aos serviços de saúde. Além do mais, a coordenação em países europeus tem logrado maior sucesso entre os que estabeleceram a APS como porta de entrada e o médico generalista como filtro - países com sistemas nacionais de saúde - (GÉRVAS, RICO, 2005), mas os mecanismos pró-coordenação têm variado, notadamente, por 
meio de incentivos financeiros. (GIOVANELLA, 2011; WADMANN; STRANDBERG-LARSEN; VRANGBEK, 2009) Ademais, o sucesso na coordenação via APS depende, também, do prestígio e credibilidade de que médicos generalistas desfrutam entre o coletivo de médicos especialistas e com a sociedade. (GÉRVAS et al., 2007; SALTMAN, 2006)

Nesse contexto, Gérvas e Rico (2005) advogam, a partir de experiências europeias, que os profissionais de primeiro contato, particularmente os médicos generalistas (general practitioners), devem agir como filtros (gatekeeper) para a atenção especializada, por meio do fortalecimento de suas ações na rede, bem como ampliação do leque de oferta de serviços. Em Portugal, por exemplo, todo médico da APS é um especialista em medicina geral e familiar, ou seja, tem uma formação compatível com outras especialidades médicas, permitindo o reconhecimento entre os pares de distintos níveis assistenciais, melhorando a resolubilidade das ações clínicas e facilitando a coordenação entre os níveis. (ROCHA; SÁ, 2011; SANTOS et al., 2015)

A argumentação a favor da coordenação sustenta-se, ainda, em ampla revisão realizada por Núñez, Lorenzo e Navarrete (2006), que sintetizam que os problemas de falta de coordenação entre os níveis assistenciais repercutem na ineficiência da gestão de recursos com duplicidade diagnóstica, encaminhamentos inadequados, má utilização das urgências hospitalares, perda de continuidade nos processos assistenciais e diminuição na qualidade da atenção prestada.

A coordenação é um atributo da APS e funciona como um amálgama, pois potencializa e viabiliza os cuidados continuados, articula os diferentes pontos no sistema para a integralidade e desburocratiza a função de primeiro contato. (STARFIELD, 2002) A coordenação parte do reconhecimento de que as diferentes necessidades das pessoas e as possibilidades de resolução não podem ser alcançadas apenas pela equipe de APS. Nesse caso, caberia aos profissionais da APS receber e reconhecer as necessidades dos usuários, responsabilizando-se pelo encaminhamento interno ou para outro serviço mais adequado, bem como estar 
em contato direto com outros profissionais (especialistas) para complementar as informações e aumentar a resolubilidade, a fim de prosseguir com o acompanhamento continuado. Nessa mesma direção, Mendes (2002) sintetiza que a coordenação implica, para a equipe de saúde da APS, reconhecer e ordenar os problemas que requerem cuidados compartilhados por profissionais de outros segmentos e, ao mesmo tempo, garantir a continuidade da atenção. Sendo assim, "a coordenação assistencial seria um atributo organizacional dos serviços de saúde que se traduz na percepção de continuidade dos cuidados na perspectiva do usuário”. (ALMEIDA et al., 2010, p. 287)

Outrossim, há necessidade de uma rede integrada, ou seja, necessita-se de um sistema que oferte diferentes serviços com graus variados de densidade tecnológica, com profissionais de diferentes formações adequadamente distribuídos e que reconheçam o papel coordenador da equipe da APS, além de usuários que busquem a APS como primeiro contato e estabeleçam vínculos com esses profissionais. Nesse quesito, abre-se uma distinção acerca da integração e coordenação, pois

a integração se expressa na organização do sistema de saúde [e] a coordenação se realiza no nível do cuidado individual [exercida] pelos profissionais de saúde no processo de atenção e se expressa em atenção contínua, centrada no paciente, adequada às suas necessidades de saúde, e oportuna - ofertada no tempo adequado. (GIOVANELLA; ESCOREL; MENDONÇA, 2009, p. 11)

A efetivação da integração dos serviços e da coordenação dos cuidados implica alguma forma de longitudinalidade por um mesmo profissional ou equipe e continuidade dos cuidados com a responsabilização pelos fluxos e contrafluxos em qualquer ponto da rede. (CONILL; FAUSTO, 2007) Tais distinções entre longitudinalidade, "presença e o uso de uma fonte habitual de atenção no decorrer do tempo", e de continuidade, "sequência de consultas nas quais há mecanismo de transferência de informação”, estão bem discutidas e delimitadas por Starfield (1980, 2002). 
Dessa forma, os sistemas públicos de serviços de saúde com forte integração têm a coordenação e a continuidade do cuidado como elementos sinérgicos, bem como sistemas com coordenação e continuidade do cuidado entre os diferentes pontos da rede resultam e/ou requerem uma adequada integração. As variações, portanto, de integração sem coordenação ou vice-versa são comuns em estratégias parciais, ou seja, sistemas públicos de saúde nos quais a universalidade e a integralidade pertencem apenas ao campo formal, pois não estão consolidadas.

Trata-se, por conseguinte, de um grande desafio, posto que a integração da rede e a coordenação dos cuidados em saúde pressupõem uma relação de interdependência entre atores sociais e organizações distintas, cada qual possuindo parcelas de recursos necessários à resolução de problemas que são comuns a toda a rede, envolvendo conflitos de interesses e disputa de poder. (ALMEIDA et al., 2010; HARTZ; CONTANDRIOPOULOS, 2004)

Esses argumentos distinguem a "coordenação dos cuidados" (coordination) de procedimentos burocráticos, como o "manejo de caso" (case management) ou o "manejo da doença" (disease-management programmes), que atendem a uma racionalidade instrumental, mais afeita ao controle dos custos - centrados nos gestores ou mercado - e/ ou fragmentação dos cuidados - centrados nos profissionais ou mercado -, muitas vezes em detrimento das reais necessidades do usuário, ao fracionar a continuidade da atenção. Programas de manejo de doença têm forte ideologia do sistema de seguros privados de saúde norte-americano; portanto, tendem a negligenciar as comorbidades, serem direcionados para indivíduos que já desenvolveram doença crônica e, por isso, são ineficientes na prevenção de doenças. (GREß et al., 2009) Do mesmo modo, o campo da saúde suplementar utiliza a integração e a coordenação, acima de tudo, como artifício para contingenciar a utilização dos serviços pelos segurados ou evitar que médicos solicitem determinados procedimentos que venham onerar as seguradoras. Esses procedimentos, que ficaram conhecidos como managed care (atenção 
gerenciada) e são utilizados em organizações de managed care por operadoras de planos de saúde privados dos Estados Unidos, foram difundidos como instrumento de organização da atenção para diversos países.

Esmiuçando essa discussão, Merhy (2002) e Merhy, Iriart e Waitzkin (1996) abordam o processo de trabalho em saúde e destrincham um panorama latino-americano da atenção gerenciada e seus desdobramentos na gestão dos serviços de saúde no Brasil, alertando acerca dos riscos de sua migração indiscriminada para o setor público. Na mesma direção, Campos e Onocko-Campos (2009, p. 233) polemizam tal situação:

[a] atenção gerenciada [...] imagina diminuir custos e aumentar a eficácia do trabalho em saúde, retirando dos profissionais, particularmente dos médicos, a capacidade de decisão sobre o próprio trabalho clínico. Esse poder é passado aos gerentes, que por meio de minuciosos protocolos - padronização de consultas diagnósticas e terapêuticas - controlam e determinam o que fazer no cotidiano dos trabalhadores.

Os diferentes argumentos para definir a melhor forma de prover os serviços de saúde - extensão do financiamento, regulação estatal, propriedade dos estabelecimentos, os meios de produção, papel do Estado como empregador, extensão da cobertura e escopo dos serviços etc. desenvolvem-se num contexto histórico e cultural de cada país, sendo elementos de disputas, consensos e alianças entre uma constelação de atores - sindicatos, associações profissionais, igreja, policy makers, usuários, mercado. (IMMERGUT, 1992; MUR-VEEMAN; VAN RAAK; PAULUS, 2008) Dessas conjunturas, emergem os sistemas de saúde e os distintos modelos de atenção à saúde, que, guiados por um conjunto de crenças, circunscrevem uma

[...] espécie de lógica que orienta a ação e organiza os meios de trabalho (saberes e instrumentos) utilizados nas práticas de saúde. Indicam um determinado modo de dispor os meios técnicocientíficos existentes para intervir sobre risco e danos à saúde. (PAIM, 2008, p. 554) 
Assim sendo, o processo de fragmentação-integração nos serviços de saúde é fruto dessas lógicas, bem como suas variadas modelagens: piramidal ou em rede, hierárquica ou em círculo, centrada no procedimento ou na produção do cuidado, competitiva ou colaborativa, fracionada ou coordenada. Oliveira, Carvalho e Travassos (2004), por exemplo, admitem a existência de uma rede, mesmo em sistemas fragmentados, pois há sempre pontos de contato e interfaces entre os serviços, bem como há permanente deslocamento das pessoas em busca de atendimento (fluxo assistenciais). Entretanto, as distinguem na forma de organização dos serviços, em "redes em árvore" ou "redes em malha". Para essas autoras,

redes em árvore, também conhecidas como redes hierárquicas (ou piramidais), caracterizam-se pela limitação das conexões entre seus diversos ramos. Predominam os fluxos hierárquicos, de um centro menor para o seu superior e, não havendo caminhos alternativos, podem ocorrer pontos de estrangulamento, impedindo o acesso da população aos níveis superiores da hierarquia. Já as redes organizadas em malha - em que cada nó se liga a vários outros - permitem percorrer caminhos variados entre os pontos, de modo que os diversos ramos da rede estão interconectados. (OLIVEIRA; CARVALHO; TRAVASSOS, 2004, p. 387)

No Brasil, os mecanismos de integração dos serviços e coordenação do cuidado respondem por princípios gerais - descentralização, regionalização e integralidade - e inúmeras estratégias de gestão - regiões de saúde, redes temáticas, linhas do cuidado, consórcio de saúde, entre outras.

Todavia, o ponto concordante deve ser a implicação na produção da saúde, convertendo, de fato, o modelo fragmentado, de baixo impacto e custos elevados, em um modelo que conceba, mediado pelo ethos social, o "cuidado como um valor" (PINHEIRO, 2009); e atenda a critérios basilares para gestão do cuidado. Os critérios imprescindíveis seriam: a busca por maior eficácia e eficiência, aumento da capacidade dos gestores e das equipes para estabelecer compromissos e contratos, produzir 
o menor dano possível - físico, mental e/ou social) -, busca de intervenções terapêuticas pedagógicas que aumentem a autonomia e o autocuidado das pessoas (efeito Paideia), por meio da gestão dos processos de trabalho. (CAMPOS, 2003)

A coordenação do cuidado via equipes de APS e a integração dos serviços em rede regionalizada de saúde são dispositivos para gestão do cuidado que, no SUS, devem ter como horizonte a garantia da integralidade. Para tanto, requerem alguns pressupostos: gestão do sistema de saúde orientada para o trabalho em rede; modelo assistencial orientado para responsabilização e vínculo entre profissionais de saúde e usuários; disponibilidade de recursos necessários à continuidade e complementação do cuidado nos pontos de distintas densidades tecnológicas; sistema de informação que dê conta da complexidade e da atualidade de um conjunto de informações. (MAGALHÃES JÚNIOR; OLIVEIRA, 2006)

Pesquisas realizadas por Dias (2012), em Belo Horizonte; Almeida e colaboradores (2010) e Giovanella e colaboradores (2009), em Aracaju, Belo Horizonte, Florianópolis e Vitória, avaliaram as estratégias de coordenação entre a APS e a atenção especializada, na perspectiva da integração entre os níveis assistenciais. As principais evidências - de forma diferenciada entre os municípios - indicam táticas que favorecem a coordenação e a integração e corroboram os pressupostos anteriormente apresentados:

1. a indução à organização e à integração da rede foi potencializada pela expansão da ESF;

2. a implantação de centros de especialidades médicas melhorou a oferta de consultas e exames, além da redução dos tempos de espera;

3. a opção pelo Sistema Nacional de Regulação (Sisreg) possibilitou conhecer o tamanho real das filas de espera, monitorá-las, planejar a oferta de atenção especializada em função da demanda, definir prioridades clínicas, monitorar o índice de 
abstenção a consultas e exames e garantiu maior imparcialidade no controle das agendas;

4. a implementação de comissão de regulação local e distrital, ou seja, incorporação da regulação à rotina dos profissionais da saúde da família;

5. a informatização dos prontuários eletrônicos melhorou a continuidade do cuidado, favoreceu a comunicação entre níveis assistenciais, permitiu o acesso rápido às informações e uma visão integral do usuário. As principais desvantagens do prontuário eletrônico foram a lentidão do sistema, segmentação dos programas, formato rígido e desatualizado e perda de informações. Além disso, é necessário integrá-lo à rede e a distintos prestadores (privados e estaduais);

6. o desenvolvimento e a aplicação de protocolos gerenciais e de protocolos clínicos, orientando o fluxo de encaminhamentos à atenção especializada;

7. as iniciativas recentes de comunicação e apoio matricial entre profissionais das Equipes de Saúde da Família (EqSF) e atenção especializada; $\mathrm{e}$

8. a contratação de serviços da rede privada, de forma complementar, para suprir deficiências na oferta da rede especializada.

O debate na literatura internacional sustenta a importância da integração dos sistemas e coordenação do cuidado. Não obstante, mesmo apresentando diretrizes gerais, a partir de revisões de literatura ou de cotejamentos entre os países, ressaltaram a necessidade de adaptação aos diferentes contextos, tendo como norte a universalização do acesso com qualidade na atenção à saúde. As pesquisas realizadas no Brasil seguem o mesmo argumento e buscam captar evidências nas experiências de gestões municipais e, assim, divulgar possibilidades de mudanças e obstáculos a serem superados para consolidação do SUS.

Nessa perspectiva, a gestão do cuidado integral em rede regionalizada é uma forma de organização do trabalho para produção do cuidado em saúde, ou seja, a operacionalização de um dado modelo de atenção à 
saúde. É uma ação política, porquanto se refere ao ato de governar pessoas, organizações e instituições, ou seja, confunde-se com o exercício do poder. É uma ação técnica, pois incorpora e opera tecnologias para organizar os serviços de saúde e lidar com situações concretas do processo saúde-doença. É uma ação ética, uma vez que a prática em saúde se dá no encontro entre sujeitos, requerendo uma tomada de posição em ato, mediada pela intersubjetividade no encontro entre trabalhador de saúde e usuário do serviço.

Sendo assim, a gestão do cuidado integral resulta de responsabilidades compartilhadas nas dimensões sistêmica, organizacional e profissional, propostas por Cecílio (2009) e retraduzidas neste livro nos níveis político-institucional, organizacional e das práticas, ou seja, catalisa a integração dos serviços e a coordenação dos cuidados. A gestão do cuidado, por conseguinte, consubstancia-se nas ações dos sujeitos - gestores, trabalhadores da saúde e usuários - em serviços de saúde integrados, formando uma rede colaborativa, ou seja, coordenada para garantir o cuidado continuado aos usuários em local apropriado e mais oportuno.

Nessa lógica, mas de forma ideal, para gestão do cuidado integral em redes regionalizadas, os profissionais da APS devem funcionar como principal porta de entrada (gatekeeper), pois: acolhem a demanda dos usuários e os acompanham em distintas necessidades, em diferentes fases da vida, de maneira regular e ao longo do tempo (longitudinalidade), os encaminham para o serviço mais apropriado quando necessário, sem perda de contato e ordenando-os por diferentes fluxos na rede de serviços (coordenação e continuidade). Para tanto, as equipes de APS requerem fluxos comunicacionais (cadastro único do usuário, protocolos clínicos, prontuários eletrônicos compartilhados, guia de referência e contrarreferência, telessaúde e outros) entre os profissionais dos distintos serviços (continuidade e integração), situados dentro e fora do território de residência (integração e regionalização), conforme a necessidade e a pertinência (eficiência). 
Porém, considerando que a integração dos serviços, a coordenação e a continuidade do cuidado são problemas presentes no SUS real, entende-se que os profissionais de saúde, ao desempenharem a gestão do cuidado nos seus diferentes níveis, deverão apresentar plasticidade no processo de trabalho, de modo a viabilizar o acesso dos usuários ao serviço necessário e em tempo oportuno. Nesse sentido, os profissionais da APS serão coordenadores do cuidado para as populações com cobertura da ESF ou que tenham, pelo menos, uma unidade básica tradicional a que possam acessar. As pessoas desprovidas de cobertura da APS ou que não conseguem acessá-las, as pessoas que buscam hospitais, serviços de pronto-atendimento ou serviços especializados precisarão ter sua demanda avaliada e ser adequadamente encaminhadas (quando possível) ou atendidas quando for necessário ou oportuno. Admite-se, assim, uma coordenação compartilhada (gestão do cuidado no nível organizacional e profissional - ação técnica e ética).

Desse modo, o status da APS como coordenadora e a integração da rede de cuidados regionalizados devem ser pensados de modo a superar os tradicionais modelos de atenção de desenho piramidal de recorte apenas burocrático. Essa perspectiva coloca todos os equipamentos de atendimento à saúde como potenciais portas de entrada do sistema, ou seja, admite-se que o mais importante é que o usuário, ao procurar um serviço, encontre resposta adequada a seu problema de saúde e seja adequadamente acolhido e encaminhado, quando necessário, ao serviço que dará seguimento e o manterá vinculado, a partir da lógica da continuidade do cuidado - nesse caso, uma unidade de saúde de APS. (CECÍLIO, 1997; MATTOS, 2009b)

A polêmica levantada não nega a APS como porta de entrada preferencial, nem tampouco deslegitima o seu papel coordenador - ainda que casual - aos demais níveis de atenção. Pelo contrário, Cecílio (1997) e Mattos (2009b) analisam os itinerários concretos dos usuários no SUS e advogam que a principal porta de entrada é o próprio trabalhador de saúde, ou seja, é na dimensão profissional/nível das práticas da gestão do 
cuidado, em qualquer ponta da rede. Desse modo, ao acolher e utilizar a tecnologia mais adequada ao problema demandado pelo usuário, o trabalhador deverá responsabilizar-se em mantê-lo - caso seja na APS - ou encaminhá-lo à APS - caso seja outro nível -, que, a partir de então, será o ponto da rede responsável pela continuidade de seus cuidados.

A suposta flexibilidade não é uma contradição à coordenação realizada pelos profissionais da APS, mas uma perspectiva crítica aos modelos que apostam na mudança top-down ou centralizam o debate na transformação da estrutura e das ferramentas de gestão e dão pouca ênfase à mudança do processo de trabalho e à micropolítica no interior das instituições. Para Franco (2009, p. 160),

a questão do acesso só será enfrentada de forma definitiva se se conseguir operar alterações estruturais no modo de produção do cuidado. Isso significa radicalizar o conceito de mudança na saúde, direcionando-a para a ruptura com o atual padrão tecnológico de produção do cuidado, que prioriza as tecnologias duras, em detrimento dos processos mais relacionais, o que tem sido a causa da sua baixa resolutividade. Esse modelo tecnológico de produção do cuidado cria a restrição ao acesso, pois é um modelo que opera centrado no ato prescritivo, nas tecnologias duras e terapêuticas medicamentosas, se caracterizando como serviços extremamente custosos, pois criam uma cadeia de consumo a partir de cada consulta médica, uma vez que o processo produtivo é centrado em insumos de maquinaria e instrumental.

Em síntese, Cecílio (1997) e Mattos (2009b) estão admitindo que a APS constitui-se como nível fundamental do cuidado ao longo da vida (longitudinalidade), mas não é o único ponto inicial de contato no momento da busca por cuidados (fluxos reais) - mormente na realidade brasileira, na qual os equipamentos de saúde na APS são insuficientes, irregularmente distribuídos, enfrentam acúmulo de demandas, há restrição no número de profissionais adequados a esse nível de atenção e, ainda, há necessidade de valorização e legitimidade dos cuidados primários pela população e pelos profissionais. 
Tais questões abordadas partem da perspectiva dos fluxos reais das pessoas em seus territórios e sustentam-se na linha dos serviços de saúde centrados no usuário (usuário-centrado). Transformar a APS em porta de entrada principal é uma meta a ser construída ao longo do tempo (WHO, 2008b), mas, no transcorrer do processo de vinculação das pessoas a esses serviços, há necessidade de uma rede atenta, responsável e acolhedora para "captar” os usuários que não fazem uso dos serviços primários e transformam, no cotidiano, os hospitais e outros equipamentos de referência em serviços de primeiro contato. Acerca dessa questão, Cecílio (1997, p. 473) indaga:

em geral, afirmamos que 'a população está entrando pela porta errada', ou não seria mais correto afirmarmos, [...], que as pessoas, diante de suas necessidades, acabam acessando o sistema por onde é possível, contrariando qualquer delírio racionalista que os técnicos do setor saúde continuam a defender sob a forma de uma pirâmide de serviços?

O relatório da OMS, em 2008, demarca e defende que as reformas de prestação de serviços a partir do movimento pela APS têm por finalidade colocar as pessoas no centro dos cuidados e, por isso, têm maiores chances de estabelecer as condições para a orientação para as pessoas, integralidade, continuidade e, assim, garantir melhores resultados em saúde, por meio de serviços que estabeleçam uma relação estável, pessoal e duradora (longitudinalidade) "entre a população e os profissionais que são o seu ponto de entrada para o sistema de saúde". (WHO, 2008b, p. 55, tradução nossa) O documento citado apresenta, ainda, uma série de evidências em diferentes países para sustentar a defesa pela APS enquanto estratégia adequada para organização dos sistemas de saúde.

Em razão disso, o argumento para a reestruturação modelar do sistema de serviços de saúde de desenho piramidal e hierárquico por outro que fomente a cooperação e interdependência entre os diferentes sujeitos de diferentes pontos sustenta-se na premissa de que aquele interdita possibilidades de integração de serviços e coordenação do cuidado 
entre os profissionais de níveis distintos, pois engendra uma distribuição de serviços de saúde baseados na suposta superioridade daqueles que estão no topo, gerando uma visão distorcida de complexidade que leva,

[...] consciente ou inconscientemente, os políticos, os gestores, os profissionais de saúde e a população, a uma sobrevalorização, seja material, seja simbólica, das práticas que são realizadas nos níveis secundários e terciários de atenção à saúde e, por consequência, a uma banalização da APS. (MENDES, 2011, p. 83)

Do ponto de vista histórico, a pirâmide de serviços de saúde foi concebida apoiada em estudos sobre a complexidade dos problemas de saúde e sua prevalência. Trata-se, portanto, de uma tradição que se tornou parâmetro para os sistemas de saúde em distintos países, especialmente por retratar uma hierarquização entre os serviços e os sujeitos, ajustar-se a diferentes interesses e a uma racionalidade epidemiológica, muitas vezes, assumida acriticamente. Em certa medida,

o que a pirâmide quereria afinal representar seria a possibilidade de uma racionalização do atendimento, de forma que haveria um fluxo ordenado de pacientes tanto de baixo para cima como de cima para baixo, realizado através dos mecanismos de referência e [contrarreferência], de forma que as necessidades de assistência das pessoas fossem trabalhadas nos espaços tecnológicos adequados. (CECÍlIO, 1997, p. 470)

Contudo, Mendes (2011) adverte, ainda, que a mudança no perfil epidemiológico não comporta mais essa compreensão. Além disso, a noção de complexidade assumida entre os níveis desloca para o topo a acepção de "maior" complexidade, pois confunde complexidade com a incorporação de tecnologias materiais e atribui a esse nível o status de maior importância, impactando o imaginário coletivo e o modelo de formação dos profissionais de saúde. Ademais, é aderente a interesses mercadológicos, uma vez que requer altos investimentos e a incorporação permanente de equipamentos, novas técnicas e novos medicamentos. 
Tais limites conceituais imprimem, ao processo formativo dos profissionais, uma valorização da técnica em detrimento do cuidado e, às práticas gestoras, uma valorização da produtividade em detrimento dos resultados. Além disso, parece fortalecer a noção de APS (primeiro nível) simplificada ou APS seletiva, justificando os altos investimentos priorizados nos demais níveis (em direção ascendente), melhores salários para os profissionais “mais” especializados em técnicas cada vez mais específicas - não necessariamente as que produzem melhores resultados sociais -, por tornar a técnica e o equipamento "um fim em si mesmos", descolados, muitas vezes, das necessidades sociais, produtores de demandas e que, por fim, acabam por modelar um sistema de saúde fragmentado.

Ainda sobre os modelos piramidais, Amaral e Campos (2011) afirmam que tais desenhos nas organizações públicas de saúde no Brasil implicam funções gerenciais mais voltadas para o controle da execução de atividades especializadas do que para a avaliação de resultados, alcance de objetivos e metas. Como consequência, a centralização das decisões, com restrito envolvimento dos trabalhadores de saúde e usuários, acarreta num baixo nível de adesão ou mesmo resiliência às tentativas de padronização e controle dos atos em saúde. Nesse sentido, a possibilidade de coordenação e comunicação entre os níveis fica impossibilitada, acarretando prejuízos, sobretudo para as pessoas que precisam de cuidados contínuos - doenças crônicas, comorbidades etc. - entre profissionais de diferentes serviços de saúde. (CALNAN; HUTTEN; TILJAK, 20o6)

Com essa discussão sobre a posição da APS e a disposição dos demais pontos nos sistemas de serviços de saúde, aposta-se na disposição em rede (MENDES, 2011) do tipo malha (OLIVEIRA; CARVALHO; TRAVASSOS, 2004) ou círculo (CECÍLIO, 1997) para efetivação da integração dos serviços - interdependência - e coordenação dos cuidados - comunicação e continuidade. Nessa direção, Longest Jr. e Young (2006) ressaltam que as organizações de saúde têm alta interdependência, sendo, portanto, a coordenação e a comunicação tarefas críticas para os gestores. A coordenação é uma maneira de lidar com a interdependência, pois, por 
meio dela, torna-se possível unir diferentes partes de uma mesma organização ou diferentes organizações que tenham uma meta em comum. Por essa razão, tem sido vista como uma das mais importantes funções dos gestores.

Além disso, quando se discute o papel da APS na rede de cuidados, deve-se considerar as heterogeneidades entre os municípios brasileiros para compreender os grandes desafios dos formuladores de políticas ( $p o-$ licy maker) e dos profissionais para viabilizar ou exercer o papel de coordenador do cuidado na rede. A coordenação do cuidado supõe que as equipes de APS não podem responder por todas as demandas da população, pois têm limites no campo técnico e tecnológico; mas devem organizar as linhas de cuidado na rede e, ao mesmo tempo, assegurar que o vínculo e o cuidado aos usuários sejam permanentes à APS. (FRANCO; MAGALHÃES JÚNIOR, 2003) Portanto,

a função de coordenação da entrada e da circulação no sistema de saúde envolve efetivamente a transformação da pirâmide dos cuidados primários numa rede, onde as relações entre a equipe de atenção primária e as outras instituições e os serviços não são baseadas somente na hierarquia topo-base e na referência de baixo para cima, mas na cooperação e na comunicação. (WHO, 2008b, p. 59, tradução nossa)

Assim, a depender dos equipamentos de cada município, a coordenação precisará extrapolar o espaço do município, pois o cuidado dar-se-á para além dos territórios de moradia do usuário.

Nessa órbita, a gestão do cuidado constituída em um determinado município precisará articular-se com a gestão do cuidado desenvolvida em outros municípios, num movimento de gestão do cuidado em redes regionalizadas. A regionalização é o princípio que contempla tal perspectiva, e os níveis da gestão do cuidado materializam-se em cenários complexos, na intersecção dos territórios e dos sujeitos. Contudo, Mattos (2009b, p. 382) alerta que 
a proposta de rede regionalizada e hierarquizada só é boa na medida em que facilite o atendimento integral das necessidades das pessoas. Exatamente por isso, não faz sentido dificultar o acesso das pessoas na tentativa de construir a rede regionalizada e hierarquizada.

Retomando-se a questão da coordenação das redes regionalizadas por equipes de APS, há características específicas que as tornam desafiadoras no Brasil. Enquanto em alguns países - Inglaterra, Portugal, Espanha, Itália e Dinamarca - com sistemas nacionais de saúde, a APS tem a função de porta de entrada obrigatória (GIOVANELLA, 2006), no Brasil, ainda não é possível do ponto de vista real. Primeiro, porque não há cobertura suficiente da ESF; segundo, porque os serviços especializados e hospitalares, além do subsistema privado, "funcionam" paralelos à coordenação da APS ou simplesmente integram-se competitivamente à rede, resilientes aos mecanismos de regulação. (FARIAS et al., 2011; PIRES et al., 2010; SERRA; RODRIGUES, 2010; VENANCIO et al., 2011)

Soma-se, também, que os profissionais da ESF não desfrutam do mesmo nível de reconhecimento profissional que os especialistas. (SISSON et al., 2011) Há distribuição inadequada dos profissionais, notadamente de médicos em municípios de pequeno porte no interior do país, o que compromete a expansão das equipes de APS. (DEMOGRAFIA..., 2013; MEDEIROS et al., 2010) Há insuficiência na oferta de algumas especialidades nas cidades de referência regionais e concentração nos grandes centros urbanos, implicando distribuição insatisfatória de determinadas consultas e procedimentos (DEMOGRAFIA..., 2013), o que impossibilita o cuidado continuado na rede e contraria as tentativas de coordenação e integração. (FARIAS et al., 2011; LOPES, 2010; PIRES et al., 2010)

Entretanto, com a expansão do número de EqSF e sua capilaridade nos diferentes territórios do país, há possibilidades concretas de que a EqSF passe a funcionar como primeiro contato (gatekeeping) e contato 
regular ao longo do tempo (longitudinalidade), ainda que com limitações ou com falhas na "filtragem" dos usuários para outros pontos da rede.

Além dos limites atribuídos à cobertura da Saúde da Família, há questões tensionadas pela rotatividade de médico e enfermeiros na ESF por conta de vínculos trabalhistas precários que comprometem o estabelecimento de vínculo com os usuários (MEDEIROS et al., 2010; SOUZA, 2011), profissionais guiados pela oferta - insuficiente e indiscriminada - de serviços especializados e de apoio diagnóstico. (PIRES et al., 2010; SERRA; RODRIGUES, 2010) Destacam-se, ainda, gestores que perseguem metas ou concentração de serviços para seu município em detrimento da equidade e dos pactos intermunicipais (LOPES, 2010; VENANCIO et al., 2011), rateio de parcas vagas, por especialidades, para as Unidades de Saúde da Família (USF) - sem levantamento de demandas -, contribuindo para a formação de filas virtuais e longos períodos de espera para exames e procedimentos. (CONILL; GIOVANELLA; ALMEIDA, 2011; SISSON et al., 2011) Nesses casos, as EqSF não exercem a função gatekeeper; ao contrário, tornam-se produtoras de demandas, ou seja, exercem o papel inverso, congestionando a capacidade de oferta - já deficiente - de consultas para especialidades e procedimentos de apoio e diagnóstico.

Em suma, a gestão do cuidado integral em redes regionalizadas de saúde volta-se para o enfrentamento desses desafios cotidianos. Nesse sentido, analisar a conformação da gestão do cuidado - nos níveis político-institucional, organizacional e das práticas de saúde - permite compreender e identificar os dispositivos facilitadores e limitantes para integração da rede de serviços de saúde e coordenação dos cuidados por equipes de APS no contexto da regionalização, a posição da ESF no processo de conformação da rede regionalizada e permite também descrever os fluxos e contrafluxos (formais e reais) configurados nos serviços de saúde. 